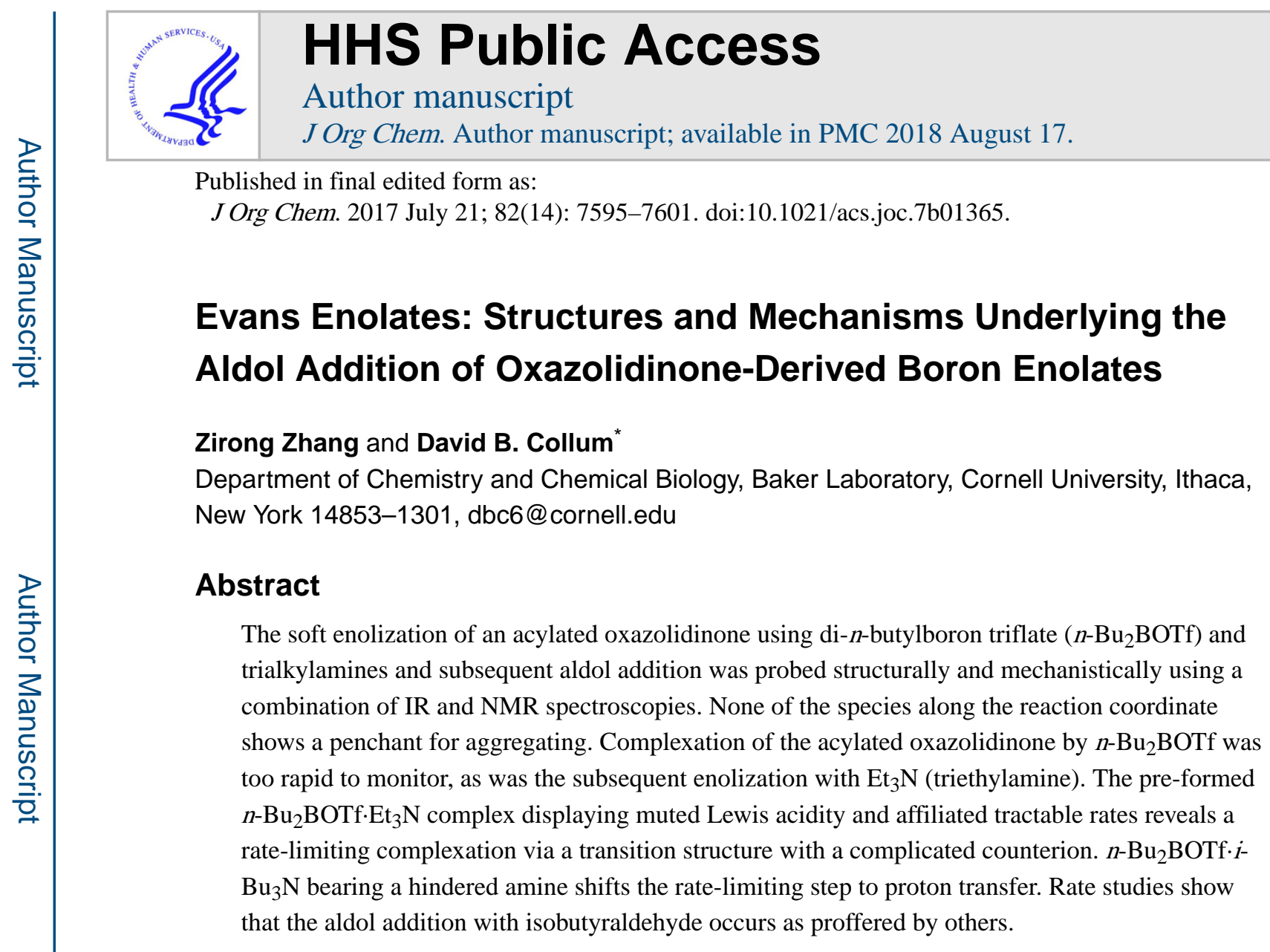

\title{
TOC Graphic
}

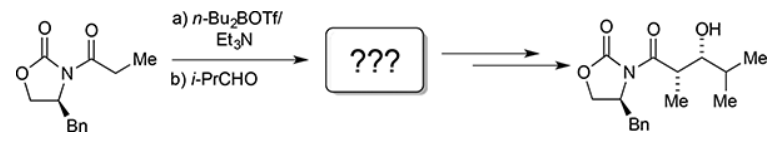

\section{Introduction}

During the development of polyketide total syntheses and the emergence of biomimetic aldol additions, few reagents have been as central as the oxazolidinone enolates, colloquially referred to as Evans enolates. ${ }^{1}$ In their seminal 1981 paper, Evans and co-workers ${ }^{2}$ showed that the acylated oxazolidinone scaffold controls additions with high facial selectivity. Although their first attempts likely involved alkali metal enolates, boron enolates derived from di- $n$-butylboron triflate ${ }^{3}$ ( $n$ - $\mathrm{Bu}_{2}$ BOTf) provide exceptional diastereoselectivities (eq 1). ${ }^{4}$ Since that first publication, Evans enolates have been reported in an astonishing 1600 patents. 5

\footnotetext{
*David B. Collum,dbc6@cornell.edu.

Supporting Information: Spectra, kinetic, and computational data and authors for reference 20. This material is available free of charge via the Internet at http://pubs.acs.org.

Notes

The authors declare no competing financial interests.
} 


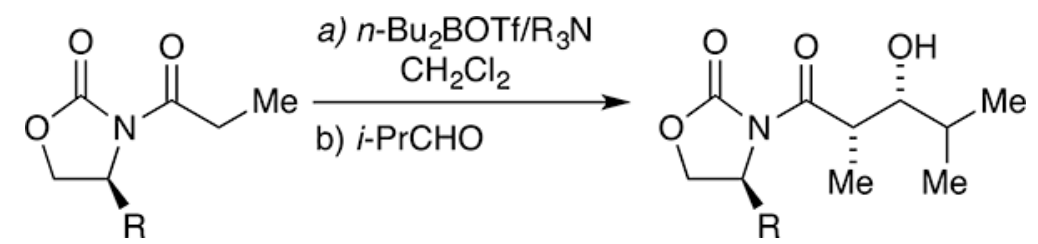

Boron enolates, including several derived from oxazolidinones, ${ }^{6}$ have been examined crystallographically, ${ }^{7}$ spectroscopically, ${ }^{7,8}$ and computationally. ${ }^{9,10}$ By contrast, few experimental probes of mechanism have been carried out with either simple boron enolates ${ }^{11}$ or oxazolidinone-based variants. ${ }^{6,12-15}$ On the heels of investigations of lithium-based aldol additions of Evans enolates, ${ }^{12}$ we undertook structural and mechanistic studies of the boron variant in Scheme $1 .^{16}$

\section{Results}

\section{Structure Determinations: General Strategies.}

The aldol addition was carried out as prescribed in the literature; ${ }^{2}$ however, $\mathrm{CHCl}_{3}$ was used interchangeably with $\mathrm{CH}_{2} \mathrm{Cl}_{2}$ owing to the convenience of $\mathrm{CDCl}_{3}$ for ${ }^{1} \mathrm{H}$ and ${ }^{13} \mathrm{C} \mathrm{NMR}$ spectroscopies. ${ }^{11} \mathrm{~B}$ NMR spectroscopy was ineffectual owing to broad, poorly resolved resonances. IR spectroscopy, by contrast, proved particularly informative; carbonyl absorbances of key species are summarized in Table 1. Representative IR spectra are contained in Figure 1. ${ }^{1} \mathrm{H}$ and ${ }^{13} \mathrm{C}$ NMR spectroscopies were used to confirm the structures of key species (supporting information).

The method of continuous variations (MCV) was used to ascertain whether key intermediates associate into higher aggregates that would otherwise go undetected with standard spectroscopic methods. ${ }^{17}$ If boron enolates are dimeric in solution, binary mixtures of two structurally related enolates would contain homodimers, $\mathbf{A}_{\mathbf{2}}$ and $\mathbf{B}_{\mathbf{2}}$ and a heterodimer, $\mathbf{A B}$ (eq 2). $\mathbf{A B}$ would appear as a new species or, in the event of rapid exchange, elicit changes in time-averaged ${ }^{1} \mathrm{H}$ or ${ }^{13} \mathrm{C}$ NMR chemical shifts. In the event, numerous binary mixtures of complexes (3), enolates (4), or alkoxides (6) derived from substrates in Chart 1 showed no evidence of $\mathbf{A B}$.

$$
\mathbf{A}_{2}+\mathbf{B}_{2} \rightleftharpoons 2 \mathbf{A B}
$$

\section{Complexation.}

The addition of 1.0 equiv of $n-\mathrm{Bu}_{2} \mathrm{BOTf}$ to oxazolidinone $1\left(0.10 \mathrm{M}\right.$ in $\left.\mathrm{CHCl}_{3}\right)$ at $20{ }^{\circ} \mathrm{C}$ resulted in approximately $50 \%$ consumption of $\mathbf{1}$ and the appearance of a single new absorbance at $1727 \mathrm{~cm}^{-1}$ corresponding to complex $\mathbf{3}$. We suspect that the electron distribution exemplified by resonance structure $\mathbf{3 a}$ (eq 3 ) accounts for the single $\mathrm{C}=\mathrm{X}$ absorbance. 
The reaction was instantaneous but not quantitative. Complete complexation was observed when the samples were either cooled with 1.1 equiv $n$ - $\mathrm{Bu}_{2} \mathrm{BOTf}$ to $-60{ }^{\circ} \mathrm{C}$ or combined with $>3.0$ equiv of $n-\mathrm{Bu}_{2} \mathrm{BOTf}$ at $20^{\circ} \mathrm{C}$ (vide infra).<smiles>CCC(=O)N1C(=O)OC[C@H]1Cc1ccccc1</smiles>

1

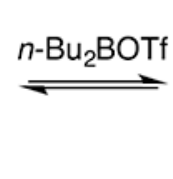<smiles>[M]CC(=O)N1C(=O)OC[C@H]1Cc1ccccc1</smiles>

3

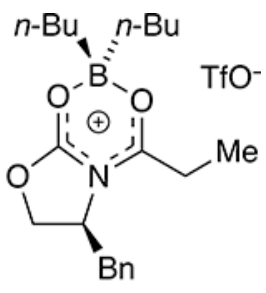

$3 a$

favored at low temperature

${ }^{1} \mathrm{H}$ NMR spectroscopy showed the two diastereotopic protons of the propionyl methylene fragment in $\mathbf{3}$ as doublets of quartets with markedly different chemical shifts ( $\delta 3.0$ and 1.7 ppm). In partially complexed samples containing only 1.0 equiv $n$-Bu ${ }_{2} \mathrm{BOTf}$, the upfield resonance appeared at $1.7 \mathrm{ppm}$ at $20^{\circ} \mathrm{C}$ and shifted to $1.4 \mathrm{ppm}$ at $-60{ }^{\circ} \mathrm{C}$. It would be tempting to ascribe this result to complexation promoted at low temperature, but the shift occurred independent of the $n$ - $\mathrm{Bu}_{2} \mathrm{BOTf}$ concentration, which also promoted complexation. We suspect that the temperature dependence stems from an aromatic $\pi$-interaction with the proximate a-proton. ${ }^{18,19}$ The analogous complex derived from $\mathbf{9}$, which bears an isopropyl moiety, showed no anomalous shifting of the proximate a proton. Density functional theory (DFT) computations ${ }^{20}$ for 3 with geometries optimized at the B3LYP/6-31G(d) level and corrected by single-point calculations at the MP2/6-31G(d)//B3LYP/6-31G(d) level did not support a proton-arene interaction.

Slow exchange on ${ }^{1} \mathrm{H}$ and ${ }^{13} \mathrm{C}$ NMR timescales made the two magnetically inequivalent $n$ butyl groups of $\mathbf{3}$ discernible. The treatment of complex $\mathbf{3}$ with $\mathbf{1}-d_{2}$ showed rapid incorporation at $-60{ }^{\circ} \mathrm{C}$ on ${ }^{1} \mathrm{H}$ NMR spectroscopy (eq 4), confirming that exchange was fast on laboratory timescales.<smiles></smiles>

3<smiles>[2H]C([2H])(C)C(=O)N1C(=O)OC[C@H]1CCCCCCc1ccccc1</smiles>

$1-d_{2}$<smiles>[2H]C(C)(C)C(=O)N1C(=O)OC[C@H]1Cc1ccccc1</smiles>

3- $d_{2}$<smiles>CCC(=O)N1C(=O)OC[C@H]1Cc1ccccc1</smiles>

1 
The results of ${ }^{19} \mathrm{~F}$ NMR spectroscopy at $-60{ }^{\circ} \mathrm{C}$ showed a single resonance $(\delta-77 \mathrm{ppm})$ consistent with a free triflate ion that shifted downfield with additional $n-\mathrm{Bu}_{2} \mathrm{BOTf}$. By comparison, $\mathrm{CF}_{3} \mathrm{SO}_{3} \mathrm{H}$ and $n-\mathrm{Bu}_{2} \mathrm{BOTf}$ displayed ${ }^{19} \mathrm{~F}$ resonances at -79 and $-76 \mathrm{ppm}$, respectively. The triflate counterion story becomes much more complicated.

\section{Enolization}

Adding triethylamine ( $\mathrm{Et}_{3} \mathrm{~N} ; 1.2$ equiv) to solutions containing $>95 \%$ complex $\mathbf{3}$ (1.1 equiv $n$ - $\mathrm{Bu}_{2} \mathrm{BOTf},-60^{\circ} \mathrm{C}$ ) afforded enolate 4 instantaneously and quantitatively, as shown by the replacement of the absorbance of $\mathbf{3}$ with two new $\mathrm{C}=\mathrm{X}$ absorbances (Table 1). Chelation by the oxazolidinone carbonyl was evidenced by the lower energy carbonyl absorbance at 1706 $\mathrm{cm}^{-1}$ (Table 1 ). The magnetically inequivalent $n$-butyl moieties of $\mathbf{4}$, however, were timeaveraged in the ${ }^{1} \mathrm{H}$ and ${ }^{13} \mathrm{C}$ NMR spectra at $-60{ }^{\circ} \mathrm{C}$, suggesting weak chelation.

\section{Tandem Complexation-Enolization}

The complexation of $\mathbf{1}$ to form $\mathbf{3}$ was too fast to monitor, as was the enolization of $\mathbf{3}$ to form enolate 4 . However, $\mathbf{1}$ reacted with a preassociated $n-\mathrm{Bu}_{2} \mathrm{BOTf} \cdot \mathrm{Et}_{3} \mathrm{~N}$ complex at $0{ }^{\circ} \mathrm{C}$ at tractable rates with no detectable pre-complex $\mathbf{3}$ owing to the attenuated (inhibited) Lewis acidity. ${ }^{21} n$-Bu $\mathrm{Bu}_{2} \mathrm{BOTf} \cdot \mathrm{Et}_{3} \mathrm{~N}$ reacted in slow exchange with free $\mathrm{Et}_{3} \mathrm{~N}$, and the ${ }^{1} \mathrm{H}$ NMR spectra confirmed the 1:1 complex noted previously. ${ }^{22,23}$

Rate studies revealed both expected and decidedly unexpected results. The conversion of $\mathbf{1}$ to enolate 4 at $0{ }^{\circ} \mathrm{C}$ under pseudo-first-order conditions $(0.0020 \mathrm{M} \mathrm{1})$ followed a first-order decay as confirmed by pseudo-first-order rate constants $\left(k_{\text {obsd }}\right)$ that were independent of the concentration of 1 . Comparing 1 and $1-d_{2}$ afforded no isotope effect $\left(k_{\mathrm{H}} / k_{\mathrm{D}}=1.00 \pm 0.01\right)$. Post-rate-limiting enolization was confirmed by two additional experiments. ${ }^{24} \mathrm{~A}$ mixture of pre-formed complexes 3 and $3-d_{2}$ (1.0 equiv each) was treated with a deficiency ( 0.80 equiv) of $\mathrm{Et}_{3} \mathrm{~N}$, thereby forcing the instantaneous deprotonation to select $\mathrm{H}$ over $\mathrm{D}$. The selective loss of 3 monitored with ${ }^{1} \mathrm{H}$ NMR showed a large competitive isotope effect $\left(k_{\mathrm{H}} / k_{\mathrm{D}}=10\right)$. To confirm that the deprotonation of $\mathbf{3}$ was faster than decomplexation-a requirement for post-rate-limiting proton transfer ${ }^{24}$ - we added low concentrations of an equimolar mixture of 1- $d_{2}$ and $\mathrm{Et}_{3} \mathrm{~N}$ to a solution of 3. Enolization proceeded to the exclusion of the exchange of 1- $d_{2}$ into 3. Conversely, adding low concentrations of an equimolar mixture of $\mathbf{1}$ and $\mathrm{Et}_{3} \mathrm{~N}$ to a solution of 3- $d_{2}$ again resulted in dominant enolization, with approximately $10 \%$ incorporation of $\mathbf{1}$ into complex $\mathbf{3}-d_{2}$. Slowing the isotopically sensitive enolization 10-fold relative to exchange with substrate revealed a $10 \%$ competing back reaction, which would have gone undetected in a measured isotope effect. ${ }^{24}$

A plot of $k_{\text {obsd }}$ versus $\mathrm{Et}_{3} \mathrm{~N}$ concentration in excess showed an approximate inverse-firstorder dependence $(n=-0.9 \pm 0.1)$ consistent with the reversible loss of the amine from $n$ $\mathrm{Bu}_{2} \mathrm{BOTf} \cdot \mathrm{Et}_{3} \mathrm{~N}$ (Figure 2). Quite unexpectedly, a plot of $k_{\mathrm{obsd}}$ versus $n$ - $\mathrm{Bu}_{2} \mathrm{BOTf} \cdot \mathrm{Et}_{3} \mathrm{~N}$ concentration in which the excess amine concentration was held constant showed a thirdorder dependence ( $n=3.3 \pm 0.3$; Figure 3$)$. We neither anticipated this result nor have a fully satisfactory explanation, as discussed below. 


$$
-\mathrm{d}[\mathbf{1}] / \mathrm{d} t=k^{\prime}[\mathbf{1}]\left[n-\mathrm{Bu}_{2} \mathrm{BOTf} \cdot \mathrm{Et}_{3} \mathrm{~N}\right]^{3}\left[\mathrm{Et}_{3} \mathrm{~N}\right]^{-1}
$$

Taken together, the reaction orders afforded the rate law in eq 5 , which implicated a transition structure with $\left[(\mathbf{1})\left(n-\mathrm{Bu}_{2} \mathrm{BOTf}\right)_{3}\left(\mathrm{Et}_{3} \mathrm{~N}\right)_{2}\right] \doteqdot$ stoichiometry. ${ }^{25}$ The triflate-based counterion denoted as " $\mathrm{X}^{-}$" at the transition state would necessarily be complicated. Neither of the two amines in the rate-limiting transition state served as a Brønsted base because the deprotonation is post-rate-limiting. We defer the interpretation of stoichiometry to the discussion; however, we probed the amine dependence and obtained the following relative reaction rates: $\mathrm{Me}_{2} \mathrm{NEt}(\mathrm{DMEA})<\mathrm{MeNEt}_{2}<\mathrm{Et}_{3} \mathrm{~N}<i-\mathrm{Pr}_{2} \mathrm{NEt}<i-\mathrm{Bu}_{3} \mathrm{~N}$.

$i$ - $\mathrm{Bu}_{3} \mathrm{~N}$ shifted the equilibrium to non-limiting behavior that has the effect of shifting the rate-limiting step to proton transfer as described by Scheme 2 and eqs 6-9. A plot of $k_{\text {obsd }}$ versus $i$-Bu 3 N concentration showed saturation kinetics (Figure 4) in which substrate and $i$ $\mathrm{Bu}_{3} \mathrm{~N}$ competitively coordinate to boron. $K_{\mathrm{eq}}$ was commensurate with a value measured with ${ }^{1} \mathrm{H}$ NMR using enolization-resistant isobutyrate $\mathbf{2 0}$ (see below) as a surrogate. The enolization of $\mathbf{1}$ using $i-\mathrm{Bu}_{3} \mathrm{~N}$ showed rate-limiting proton transfer, as evidenced by a large kinetic isotope effect $\left(k_{\mathrm{H}} / k_{\mathrm{D}}=10\right)$ at low and high amine concentrations. Changing the addition sequence by adding $i$ - $\mathrm{Bu}_{3} \mathrm{~N}$ to the substrate-boron complex provided the same behavior. The counterintuitive normal (rather than inverse) saturation owing to an unproductive side equilibrium stemmed from the dual role of amine as both inhibiting Lewis base and accelerating Brønsted base.

$$
\begin{gathered}
\mathrm{d}[\mathbf{4}] / \mathrm{d} t=k_{\text {obsd }}\left[\mathbf{1}_{\text {total }}\right] \\
k_{\text {obsd }}=k_{2} K_{\text {eq }}\left[n-\mathrm{Bu}_{2} \mathrm{BOTf} \cdot i-\mathrm{Bu}_{3} \mathrm{~N}\right] /\left\{1+K_{\text {eq }}\left[n-\mathrm{Bu}_{2} \mathrm{BOTf} \cdot i-\mathrm{Bu}_{3} \mathrm{~N}\right] /\left[i-\mathrm{Bu}_{3} \mathrm{~N}\right]\right\}
\end{gathered}
$$

\section{Low Amine Concentration}

$$
k_{\text {obsd }}=k_{2}\left[i-\mathrm{Bu}_{3} \mathrm{~N}\right]
$$

High Amine Concentration

$$
k_{\mathrm{obsd}}=k_{2} K_{\mathrm{eq}}\left[n-\mathrm{Bu}_{2} \mathrm{BOTf} \cdot i-\mathrm{Bu}_{3} \mathrm{~N}\right]
$$

\section{Aldol Addition.}

The reaction of enolate $4(0.10 \mathrm{M})$ and excess $\mathrm{Et}_{3} \mathrm{~N}(0.020 \mathrm{M})$ with $i$-PrCHO $(0.13 \mathrm{M})$ in $\mathrm{CH}_{2} \mathrm{Cl}_{2}$ at $-78{ }^{\circ} \mathrm{C}$ afforded adduct 6 at tractable rates. The absence of chelation in alkoxide 
6 was shown by carbonyl absorbances that were nearly indistinguishable from those of starting oxazolidinone 1 . The absence of aggregation was shown experimentally using MCV (vide supra) and supported by DFT computations predicting the dimerization of alkoxide 6 (eq 10) to be highly endothermic. ${ }^{26}$

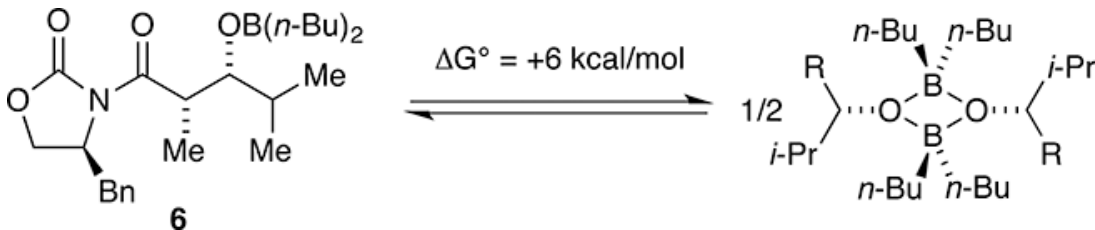

Reactions under pseudo-first-order conditions (0.0050 M enolate 4 and $0.050 \mathrm{M} i$-PrCHO) showed first-order decays of enolate and $k_{\text {obsd }}$ that were independent of the initial enolate concentration (Figure 5). The rate was unaffected by excess $\mathrm{Et}_{3} \mathrm{~N}$ or added tetrahydrofuran. The rate law in eq 11 is consistent with a simple aldol addition mechanistically akin to that proposed by Evans in the original work (5 in Scheme 1). DFT studies mirroring those reported by Kobayashi and co-workers ${ }^{6}$ showed transition structure $\mathbf{5 a}$ to be both viable and $4.7 \mathrm{kcal} / \mathrm{mol}$ more stable than transition structure $\mathbf{5 b}$ leading to the wrong isomer. ${ }^{1,2}$

$$
-\mathrm{d}[\mathbf{4}] / \mathrm{d} t=k^{\prime}[\mathbf{4}][i-\mathrm{PrCHO}]
$$

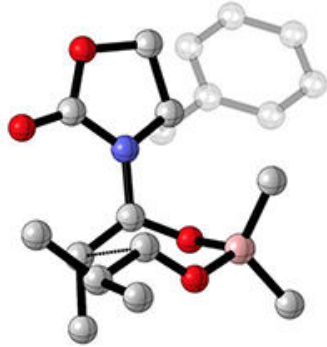

5a

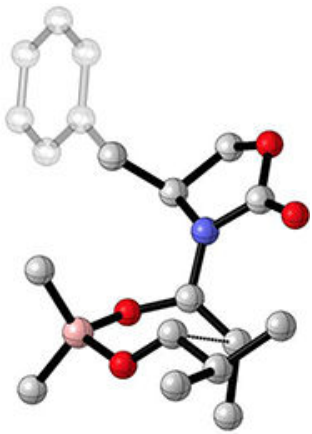

$\mathbf{5 b}$

\section{Discussion}

The structural and mechanistic studies of the Evans boron aldol addition proceeded largely according to conventional wisdom. Treating oxazolidinone $\mathbf{1}$ at $20^{\circ} \mathrm{C}$ with $n-\mathrm{Bu}_{2} \mathrm{BOTf}$ causes the instantaneous formation of complex 3 . Full complexation requires cooling to $-60{ }^{\circ} \mathrm{C}$ or the use of excess $n-\mathrm{Bu}_{2} \mathrm{BOTf}$ at $20^{\circ} \mathrm{C}$. Treatment of $\mathbf{3}$ with trialkylamines at $-78{ }^{\circ} \mathrm{C}$ effects instantaneous enolization to give boron enolate 4 . Aldol addition to $i$-PrCHO at $-60{ }^{\circ} \mathrm{C}$ affords boron alkoxide 6 . 
IR spectroscopy provided compelling support for the chelates in $\mathbf{3}$ and $\mathbf{4}$, whereas the carbonyl of $\mathbf{6}$ does not coordinate to boron. Computations were in full accord with the monomeric alkoxide $6 .{ }^{26} \mathrm{MCV}$ also provided no evidence that 3, 4, or 6 aggregate.

The high rates of complexation and enolization were overcome using $n$ - $\mathrm{Bu}_{2} \mathrm{BOTf} \cdot \mathrm{Et}_{3} \mathrm{~N}$ mixtures, which caused a marked attenuation of the complexation rate. The rate studies confirmed a rate-limiting complexation followed by rapid (post-rate-limiting) enolization. The success of the standard boron aldol addition stems from the fact that the incomplete 1-3 equilibrium is driven to enolate 4 by the enolization. Switching to $n-\mathrm{Bu}_{2} \mathrm{BOTf} \cdot i-\mathrm{Bu}_{3} \mathrm{~N}$ displaces the equilibrium toward observable complex $\mathbf{3}$ and shifts the rate-limiting step to proton transfer (Scheme 2). ${ }^{23}$

The details of the complexation are very odd. Although complex 3 represents a simple $\mathrm{CF}_{3} \mathrm{SO}_{3}{ }^{-}$(" $\mathrm{X}^{-")}$, a third-order dependence on $n-\mathrm{Bu}_{2} \mathrm{BOTf} \cdot \mathrm{Et}_{3} \mathrm{~N}$ in conjunction with an inverse-first-order dependence on amine implicates a rate-limiting transition structure with an unexpected $\left[\left(n-\mathrm{Bu}_{2} \mathrm{BOTf}\right)_{3}\left(\mathrm{Et}_{3} \mathrm{~N}\right)_{2}(\mathbf{1})\right] \ddagger$ stoichiometry. ${ }^{25,27}$ Chart 2 shows a number of fragments - possible building blocks - that could be in play ranging from highly plausible to merely conceivable. The titration of $n$ - $\mathrm{Bu}_{2} \mathrm{BOTf}$ with $\mathrm{Et}_{3} \mathrm{~N}$ clearly shows a 1:1 complex consistent with 15. A single $n$-Bu group excludes the ion pair of $\mathbf{1 6}$ and $\mathbf{1 7}$. Dimer $\mathbf{1 8}$ is supported by limited literature precedent, ${ }^{28}$ but it offers us nothing useful. The 3:2 stoichiometry demands a reactive form such as that composed of Lewis acidic $\mathbf{1 6}$ and counterion 19 with five-coordinate borons. The evidence of five-coordinate boron is sound $^{29}$. We piece this together into to create transition structure $\mathbf{2 0}$ for rate-limiting complexation. The five-coordinate, trigonal bipyramidal substitution at boron has strong precedent from some rate studies we did a dozen years ago on imine activation by $\mathrm{BF}_{3}-\mathrm{R}_{3} \mathrm{~N}$ complexes. ${ }^{30}$ The complex genenion remains the controversial portion. And, as a referee noted, if the third-order dependence in Figure 3 is actually a second-order dependence that is in error-it happens - one can replace gegenion 19 with the far more conventional 17. It would be an understatement to say that we are uneasy about parts of the model.

As an aside, the kinetics using the $n-\mathrm{Bu}_{2} \mathrm{BOTf} \cdot i-\mathrm{Pr}_{2} \mathrm{NEt}$ bearing a more hindered trialkylamine to form enolate 4 shows a 30-fold acceleration relative to the kinetics with the $\mathrm{Et}_{3} \mathrm{~N}$ variant, as expected for a mechanism requiring an amine dissociation. Interestingly, the measured reaction order in $n$ - $\mathrm{Bu}_{2} \mathrm{BOTf} \cdot i-\mathrm{Pr}_{2} \mathrm{NEt}$ approaches unity $(n=1.3)$. The complex counterion may be unfavorable if the cation fragment (analogous to 16) becomes too congested.

The final step - the aldol addition of 4 to give $\mathbf{6}$ via transition structure 5 (Scheme 1) - is mechanistically uneventful. Neither $\mathrm{Et}_{3} \mathrm{~N}$ nor added tetrahydrofuran inhibits the reaction, which shows that the putative four-coordinate boron in $\mathbf{4}$ is undisturbed by Lewis basic ligands. Kobayashi and co-workers ${ }^{6}$ carried out calculations probing the nuances of $\mathbf{5}$ and competing orientations. These reactions showed consistency in the open transition structure and approach of the aldehyde anti to the benzyl group. 


\section{Conclusion}

We described studies of the boron enolate-based Evans aldol addition. The most surprising aspect proves to be the mechanism of complexation, in which we may have uncovered some unusual organoboron coordination chemistry. The potentially most useful part, however, is probably the insights gained about the dual role of trialkylamines as inhibitorscomplexants to the Lewis acid—and Bronsted bases. Suspecting that we could use this information to optimize the quaternization of the a-carbon using boron enolates, ${ }^{4}$ we formed complex 22 from isobutyryl derivative 21. The addition of $\mathrm{Et}_{3} \mathrm{~N}$ pushes the equilibrium to $\mathbf{2 1}$ rather than enolate $\mathbf{2 3}$, however. More hindered trialkylamines promote complexation but are too unreactive as Brønsted bases. Thus, the quaternization faces challenges posed by such soft enolization methods.

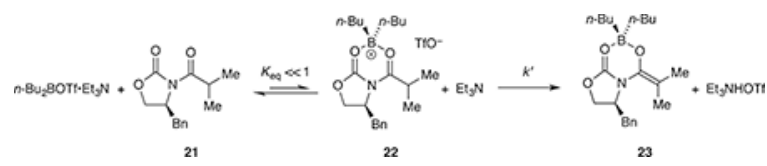

It seems generally useful, even advisable, to understand the structural and mechanistic principles underlying synthetically prevalent reactions such as the Evans aldol addition.

\section{Experimental}

\section{Reagents and Solvents.}

$\mathrm{CH}_{2} \mathrm{Cl}_{2}, \mathrm{CHCl}_{3}$, and $\mathrm{CDCl}_{3}$ were distilled from molecular sieves. Trialkylamines were distilled from sodium benzophenone ketyl. $n$-Bu $\mathrm{B}_{2} \mathrm{BOTf}$ was used as a neat oil by evaporating the solvent from a commercial $1.0 \mathrm{M} \mathrm{n}$ - $\mathrm{Bu}_{2} \mathrm{BOTf}$ solution in $\mathrm{CH}_{2} \mathrm{Cl}_{2}$. Air- and moisturesensitive materials were manipulated under argon using standard glovebox, vacuum line, and syringe techniques. Oxazolidinones $\mathbf{1}$ and 7-11 were either purchased or prepared as described previously. ${ }^{31}$

\section{NMR Spectroscopy.}

An NMR tube under vacuum was flame-dried on a Schlenk line and allowed to return to room temperature, backfilled with argon, and placed in a $-78^{\circ} \mathrm{C}$ dry ice/acetone bath. The appropriate amounts of $n-\mathrm{Bu}_{2} \mathrm{BOTf}, \mathrm{Et}_{3} \mathrm{~N}$, and oxazolidinone in $\mathrm{CDCl}_{3}$ were added sequentially via syringe. The tube was flame-sealed under partial vacuum, mixed on a vortex mixer three times for $\sim 10 \mathrm{~s}$ with cooling between each vortexing, and stored in a freezer at $-80{ }^{\circ} \mathrm{C}$. Standard $1 \mathrm{H}, 13 \mathrm{C}$, and ${ }^{19} \mathrm{~F}$ NMR spectra were recorded on a $500 \mathrm{MHz}$ spectrometer at 500,125 , and $470 \mathrm{MHz}$, respectively. The $1 \mathrm{H}, 13 \mathrm{C}$, and ${ }^{19} \mathrm{~F}$ resonances are referenced to $\mathrm{CDCl}_{3}\left(\mathrm{CHCl}_{3} 7.26\right.$ and $\left.\mathrm{CDCl}_{3} 77.16 \mathrm{ppm}\right)$ and fluorobenzene (-113.15 ppm).

\section{IR spectroscopic analyses.}

IR spectra were recorded with an in situ IR spectrometer fitted with a 30-bounce, silicontipped probe. The spectra were acquired in 16 scans at a gain of 1 and a resolution of $4 \mathrm{~cm}$ ${ }^{-1}$. A representative reaction was carried out as follows: The IR probe was inserted through a nylon adapter and O-ring seal into an oven-dried, cylindrical flask fitted with a magnetic stir 
bar and a T-joint. The T-joint was capped with a septum for injections and a nitrogen line. After evacuation under full vacuum, heating, and flushing with nitrogen, the flask was charged with $\mathrm{CHCl}_{3}$ and cooled in a $-60{ }^{\circ} \mathrm{C}$ bath prepared with fresh acetone. After a background spectrum was recorded, oxazolidinone $1(23.3 \mathrm{mg}, 0.10 \mathrm{mmol})$ was added as a 1.0 M solution in $\mathrm{CHCl}_{3}$ with stirring, followed by neat $n$ - $\mathrm{Bu}_{2} \mathrm{OTf}(30.2 \mathrm{mg}, 0.11 \mathrm{mmol})$, neat $\mathrm{Et}_{3} \mathrm{~N}$ (12.1 mg, $\left.0.12 \mathrm{mmol}\right)$, and $i$-PrCHO $(9.4 \mathrm{mg}, 0.13 \mathrm{mmol})$. IR spectra were recorded every $15 \mathrm{~s}$ with monitoring of the absorbance at $1777 \mathrm{~cm}^{-1}$ and $1658 \mathrm{~cm}^{-1}$ over the course of the reaction.

\section{Acknowledgments.}

We thank the National Institutes of Health (GM077167) for support.

\section{References and Footnotes}

1. (a) Evans DA ; Shaw JT L'actualité Chimique 2003, 35.(b) Lin G-Q ; Li Y-M ; Chan ASC Principles and Applications of Asymmetric Synthesis, Wiley \& Sons: New York, 2001; 135.(c) Modern Aldol Reactions, Vols. 1 and 2 (Ed.: Mahrwald R ), Wiley-VCH, Weinheim, 2004.

2. Evans DA ; Bartroli J ; Shih TL J. Am. Chem. Soc 1981, 103, 2127.

3. The term "triflate" derives from the University of California, Berkeley and was cinematically inspired by science fiction movie, The Day of the Triffids. Charles Wilkins, personal communication.

4. (a) Cowden C J. Org. React 1997, 51, 1.(b) Abiko A In Boron Reagents in Synthesis: ACS Symposium Series; American Chemical Society: Washington, DC, p 123, 2016.

5. Evans DA ; Kim AS ; Skrydstrup T ; Taaning RH (S)-4-Benzyl-2-oxazolidinone; John Wiley \& Sons, New York; p 1-18, 2007.

6. (a) Makino Y ; Iseki K ; Fujii K ; Oishi S ; Hirano T ; Kobayashi Y Tetrahedron Lett. 1995, 36, 6527.(b) Shinasha CB ; Sunoj RB J. Am. Chem. Soc 2010, 132, 12319. [PubMed: 20707387] (c) Sreenithya A ; Sunoj RB Org. Lett 2012, 14, 5752. [PubMed: 23116155] (d) Shinisha CB ; Sunoj RB Org. Lett 2010, 12, 2868. [PubMed: 20503998]

7. Ma L ; Hopson R ; Li D ; Zhang Y ; Williard PG Organometallics 2007, 26, 5834.

8. (a) Abiko A ; Inoue T ; Masamune S J. Am. Chem. Soc 2002, 124, 10759. [PubMed: 12207531] (b) Bai J ; Burke LD ; Shea KJ J. Am. Chem. Soc 2007, 129, 4981. [PubMed: 17388588]

9. For selected recent computational studies of boron enolates, see: (a) Dias LC ; Pinheiro SM ; Oliveira VM ; Ferreira MAB ; Tormena CF ; Aguilar AM ; Zukerman-Schpector J ; Tiekink ERT Tetrahedron 2009, 65, 8714.(b) Paton RS ; Goodman JM J. Org. Chem 2008, 73, 1253. [PubMed: 18211083] (c) Dias LC ; de Lucca EC ; Ferreira MAB ; Garcia DC ; Tormena J. Org. Chem 2012, 77, 1765. [PubMed: 22235771] (d) Paton RS ; Goodman JM Org. Lett 2006, 8, 4299. [PubMed: 16956211]

10. For a review of theoretical studies of boron enolates, see: Domingo LR ; Andres J In The Chemistry of Metal Enolates; Rappoport Z , Ed.; Wiley: New York, 2009; Vol. 1, Chapter 1.

11. Cergol KM ; Jensen P ; Turner P ; Coster MJ Chem. Commun 2007, 1363.

12. (a) Tallmadge EH ; Collum DB J. Am. Chem. Soc 2015, 137, 13087. [PubMed: 26437278] (b) Tallmadge EH ; Jermaks J ; Collum DB J. Am. Chem. Soc 2016, 138, 345. [PubMed: 26639525]

13. (a) Danda H ; Hansen MM ; Heathcock CH J. Org. Chem 1990, 55, 173.(b) Baringhaus K-H ; Matter H ; Kurz M J. Org. Chem 2000, 65, 5031. [PubMed: 10956490] (c) Evans DA ; Nelson JV ; Vogel E; Taber TR J. Am. Chem. Soc 1981, 103, 3099.(d) Kimball DB ; Michalczyk R ; Moody E ; Ollivault-Shiflett M ; De Jesus K ; Silks LA J. Am. Chem. Soc 2003, 125, 14666. [PubMed: 14640616]

14. Connolly TJ ; Hansen EC ; MacEwan MF Org. Process Res. Dev 2010, 14, 466. 
15. A copper complex of an acylated oxazolidinone shows similar IR absorbances: (a) Evans DA ; Scheidt KA ; Johnston JN ; Willis MC J. Am. Chem. Soc 2011, 123, 4480.(b) Evans DA ; Miller SJ ; Lectka T ; von Matt P J. Am. Chem. Soc 1999, 121, 7559.

16. For an excellent review of soft enolization, see: Evans DA ; Shaw JT http://isites.harvard.edu/fs/ docs/icb.topic93502.files/Lectures_and_Handouts/25-Handouts/SoftEnolization_draft.pdf

17. Renny JS ; Tomasevich LL ; Tallmadge EH ; Collum DB Angew. Chem., Int. Ed 2013, 52, 11998.

18. Martin NH ; Allen NW ; Moore KD ; Vo LJ Molec. Struct. (Theochem) 1998, 454, 161.

19. Evans invoked $\pi$ stacking during oxazolidinone-derived enolate functionalizations: Evans DA ; Chapman KT ; Hung DT ; Kawaguchi AT Angew. Chem., Int. Ed 1987, 26, 1184.

20. Frisch MJ ; et al. GaussianVersion 3.09; revision A.1; Gaussian, Inc.: Wallingford, CT, 2009.

21. Ma Y ; Lobkovsky E ; Collum DB J. Org. Chem 2005, 70, 2335. [PubMed: 15760225]

22. For NMR spectroscopic studies of $\mathrm{BF}_{3} / \mathrm{R}_{3} \mathrm{~N}$ complexes, see: Hartman JS ; Yuan $\mathrm{Z}$; Fox A ; Nguyen A Can. J. Chem 1996, 74, 2131.

23. For a discussion and leading references to ligand substitutions of $\mathrm{BR}_{3}$ derivatives, see: Toyota $\mathrm{S}$; Futawaka T ; Asakura M ; Ikeda H ; Oki M Organometallics 1998, 17, 4155.

24. For discussions of monitoring post-rate-limiting steps and the implications of rate limitation, see: (a) Simmons EM ; Hartwig JF Angew. Chem., Int. Ed 2012, 51, 3066.(b) Algera RF ; Gupta L ; Hoepker AC ; Liang J ; Ma Y ; Singh KJ ; Collum DB J. Org. Chem 2017, 82, 4513. [PubMed: 28368117]

25. The rate law provides the stoichiometry of the transition structure relative to that of the reactants: (a) Edwards JO ; Greene EF ; Ross J J. Chem. Educ 1968, 45, 381.(b) Collum DB ; McNeil AJ ; Ramírez A Angew. Chem., Int. Ed 2007, 46, 3002.

26. (a) Vorontsova LG ; Chizhov OS ; Vasil'ev LS ; Mikhailov BM Izvest. Akad. Nauk. SSSR 1981, 353.(b) Gurskii ME ; Shashkov AS ; Mikhailov BM J. Organometal. Chem 1980, 199, 171.

27. Evans traced the need for excess Lewis acid in soft enolizations to ate complexes: (a) aluminum: Evans DA ; Allison BD ; Yang MG ; Masse CE J. Am. Chem. Soc 2001, 123, 10840. [PubMed: 11686685] (b) boron: personal communication.

28. (a) Jordan E ; Lestel L ; Boileau S ; Cheradame H ; Gandini A Makromolecular Chem. 1989, 190, 267.(b) Papp R ; Somoza FB ; Sieler J ; Blaurock S ; Hey-Hawkins E J. Organometal. Chem 1999, $585,127$.

29. (a) Miyamoto K ; Yokota Y ; Suefuji T ; Yamaguchi K ; Ozawa T ; Ochiai M Chem.-Eur. J 2014, 20, 5447. [PubMed: 24644216] (b) Uruichi M ; Yakushi K ; Yamashita Y J. Materials Chem 2000, 10, 2716.(c) Chaudhuri MK ; Das B Inorg. Chem 1985, 24, 2580.(d) Brownstein S Can. J. Chem 1967, 45, 2403.(e) Koner S ; Ghosh A ; Chaudhuri NR Bull. Chem. Soc. Japan 1990, 63, 2387.

30. Aubrecht KB ; Winemiller MD ; Collum DB J. Am. Chem. Soc 2000, 122, 11084.

31. Oxazolidinones: (a) 8: Evans DA ; Britton TC ; Dorow RL ; Dellaria JF Tetrahedron 1988, 44, 5525.(b) 11: Perry MA ; Trinidad JV ; Rychnovsky SD Org. Lett 2013, 15, 472. [PubMed: 23323958] (c) 12: Szostak M ; Spain M ; Eberhart AJ ; Procter DJ J. Am. Chem. Soc 2014, 36, 2268.(d) 13: Evans DA ; Mathre DJ ; Scott WL J. Org. Chem 1985, 50, 1830. 

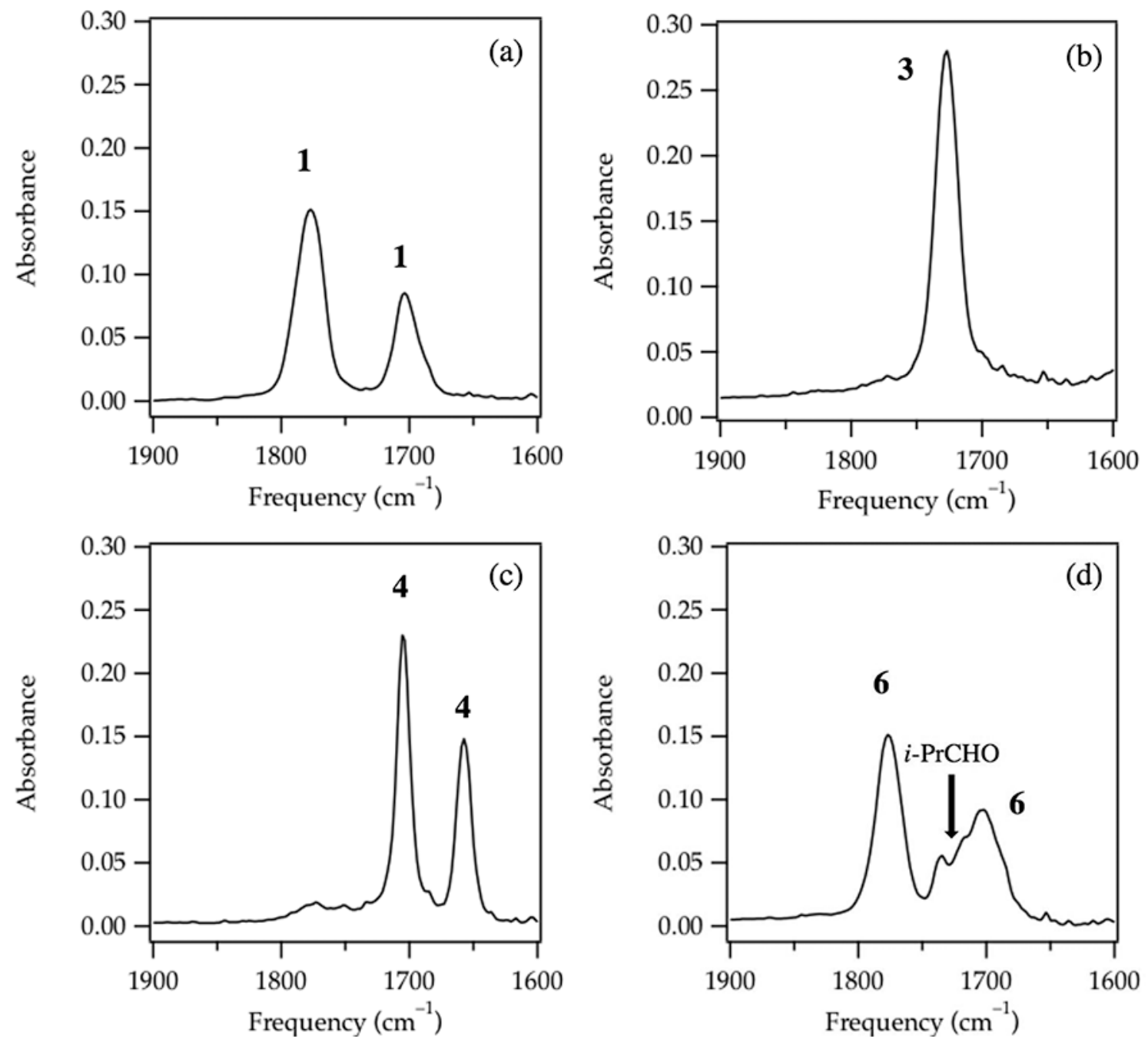

Figure 1.

IR spectra of $0.10 \mathrm{M} 1$ in $\mathrm{CHCl}_{3}$ recorded at $-60{ }^{\circ} \mathrm{C}$ with (a) no additive, (b) $0.11 \mathrm{M} n$ $\mathrm{Bu}_{2}$ BOTf affording 3, (c) $0.11 \mathrm{M} n$-Bu ${ }_{2}$ BOTf and $0.12 \mathrm{M} \mathrm{Et}_{3} \mathrm{~N}$ affording 4, and (d) $0.11 \mathrm{M}$ $n$ - $\mathrm{Bu}_{2}$ BOTf, $0.12 \mathrm{M} \mathrm{Et}_{3} \mathrm{~N}$, and 0.13 $\mathrm{M} i$-PrCHO affording 6. 


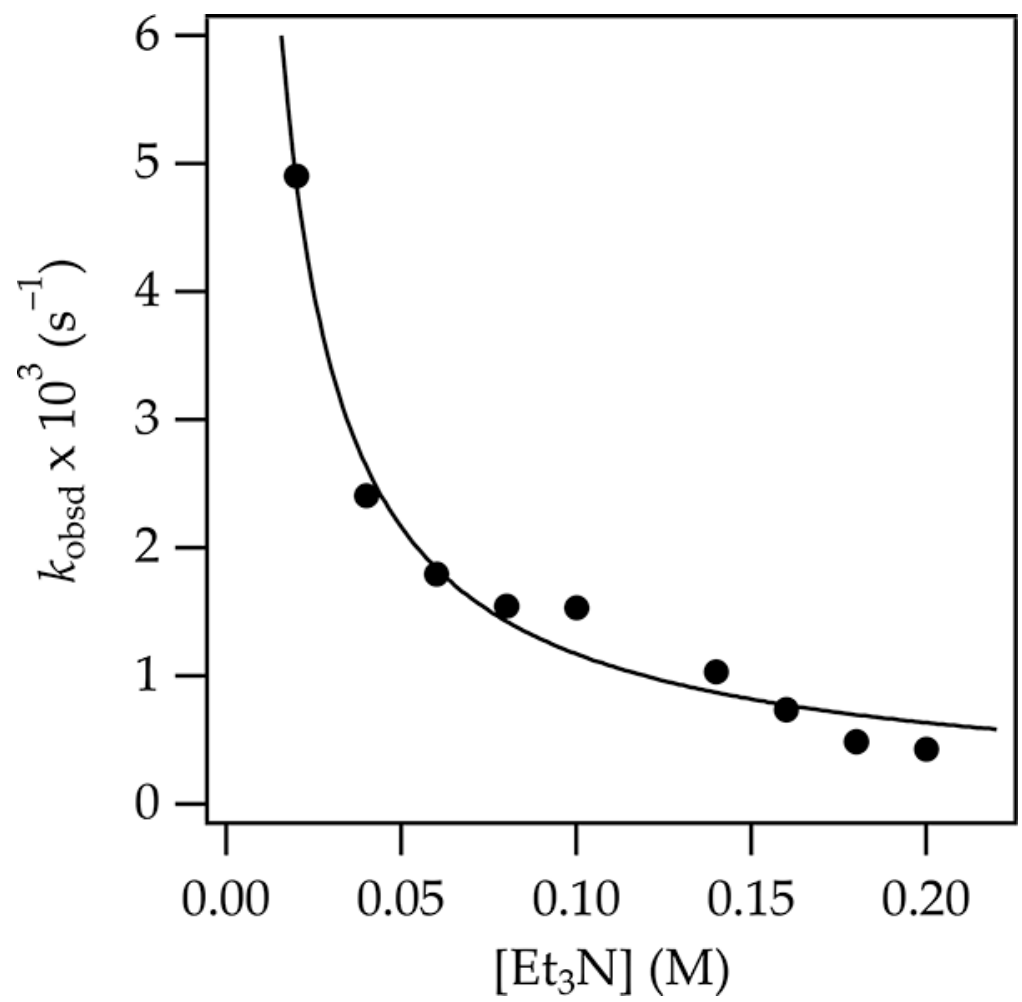

Figure 2.

Plot of $k_{\text {obsd }}$ versus added $\mathrm{Et}_{3} \mathrm{~N}$ concentration for the enolization of $1(0.0020 \mathrm{M})$ by $n$ $\mathrm{Bu}_{2} \mathrm{BOTf} \cdot \mathrm{Et}_{3} \mathrm{~N}(0.040 \mathrm{M})$ in $\mathrm{CHCl}_{3}$ at $0{ }^{\circ} \mathrm{C} . y=a x^{b}, a=0.00015 \pm 0.00003, b=-0.88$ \pm 0.05 . 


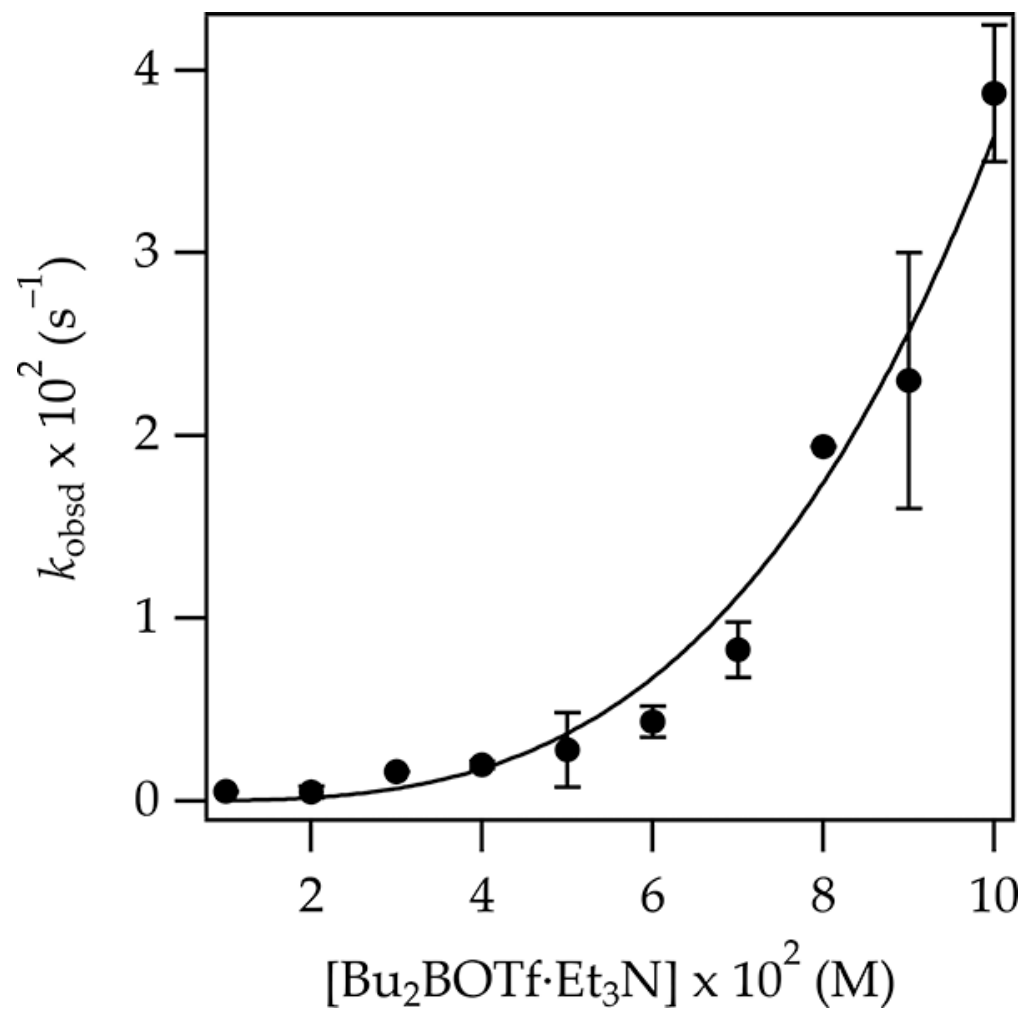

Figure 3.

Plot of $k_{\text {obsd }}$ versus $n$-Bu $\mathrm{Bu}_{2} \mathrm{BOTf} \cdot \mathrm{Et}_{3} \mathrm{~N}$ concentration for the enolization of $\mathbf{1}(0.0020 \mathrm{M})$ by $0.10 \mathrm{M}$ free (uncomplexed) $\mathrm{Et}_{3} \mathrm{~N}$ in $\mathrm{CHCl}_{3}$ at $0{ }^{\circ} \mathrm{C} . y=a x^{b}, a=72 \pm 3, b=3.3 \pm 0.3$. 


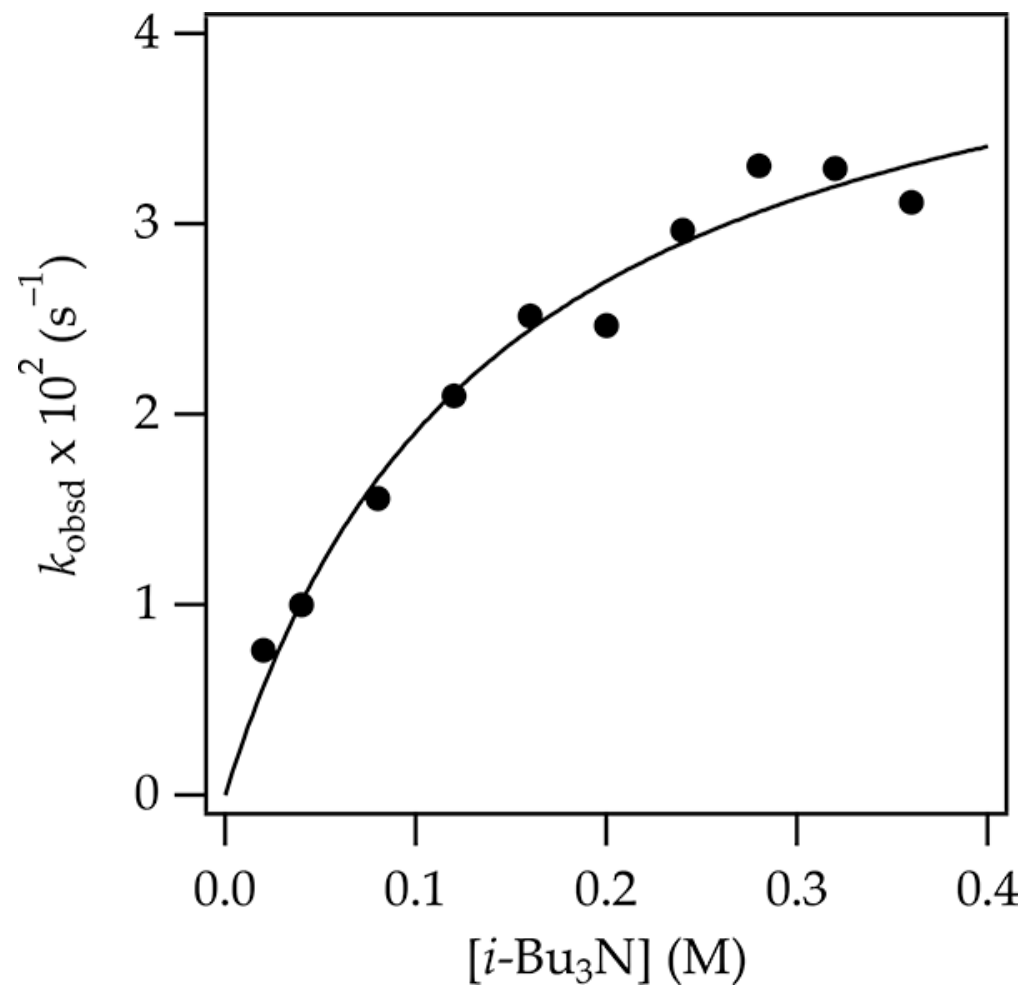

Figure 4.

Plot of $k_{\text {obsd }}$ versus $i-\mathrm{Bu}_{3} \mathrm{~N}$ concentration for the enolization of $1(0.0020 \mathrm{M})$ by $n$ $\mathrm{Bu}_{2} \mathrm{BOTf} \cdot i-\mathrm{Bu}_{3} \mathrm{~N}(0.040 \mathrm{M})$ and $i-\mathrm{Bu}_{3} \mathrm{~N}$ in $\mathrm{CHCl}_{3}$ at $0{ }^{\circ} \mathrm{C} . y=a x /(x+b), a=0.046 \pm 0.004$, $b=0.14 \pm 0.03$. 


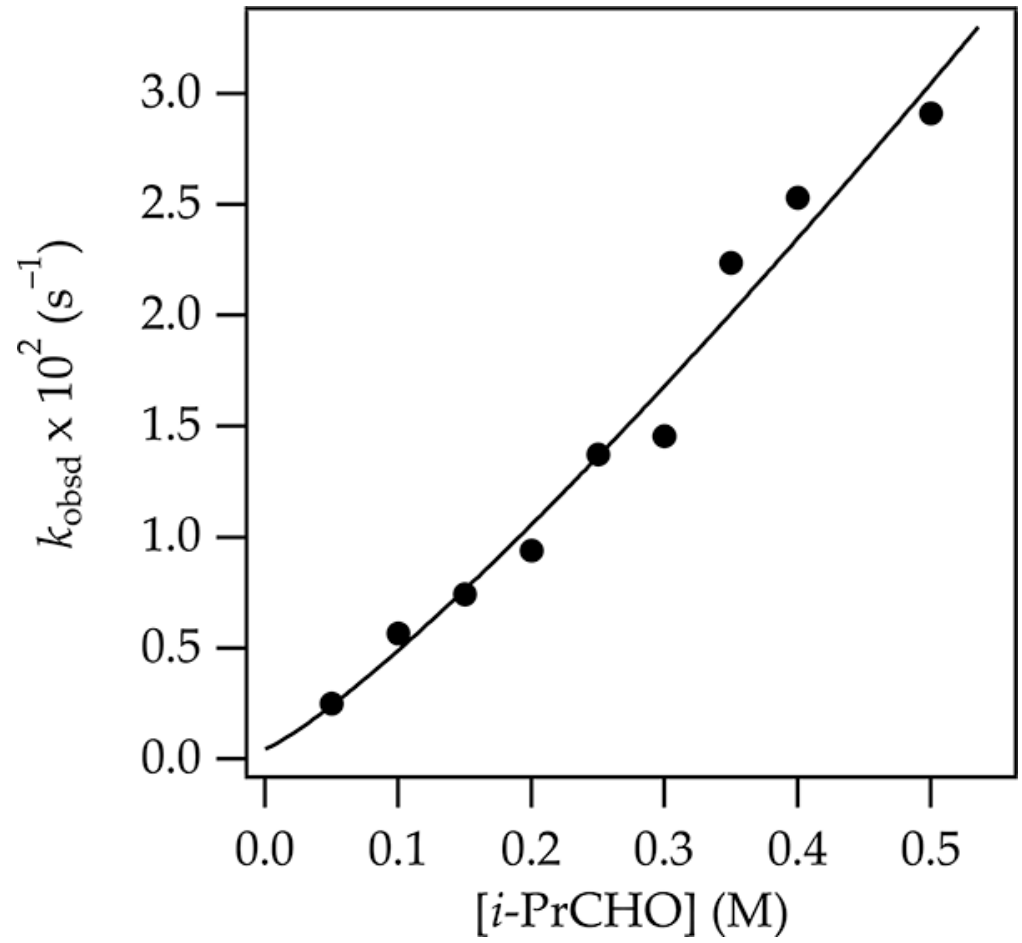

Figure 5.

Plot of $k_{\text {obsd }}$ versus $i$-PrCHO concentration for aldol addition by enolate $4(0.0050 \mathrm{M})$ with a slight $(0.0010 \mathrm{M})$ excess of $\mathrm{Et}_{3} \mathrm{~N}$ in $\mathrm{CHCl}_{3}$ at $-60{ }^{\circ} \mathrm{C} . y=a x^{b}, a=0.067 \pm 0.007, b=1.09$ \pm 0.10 . 
<smiles>[R]CC(=O)N1C(=O)OC[C@@H]1Cc1ccccc1</smiles><smiles>[R]C1COC(=O)N1C(=O)CC</smiles>

$$
\begin{aligned}
& \text { 1; } R=M e \\
& \text { 7; } R=H \\
& \text { 8; } R=t-B u
\end{aligned}
$$<smiles>O=C(CCc1ccccc1)N1C(=O)OC[C@H]1Cc1ccccc1</smiles>

12
9; $\mathrm{R}=i-\mathrm{Pr}$

10; $R=P h$

11; $\mathrm{R}=\mathrm{CH}(\mathrm{Ph})_{2}$<smiles>C[C@H]1[C@H](c2ccccc2)OC(=O)N1C(=O)CCc1ccccc1</smiles>

Chart 1.

Enolate precursors 


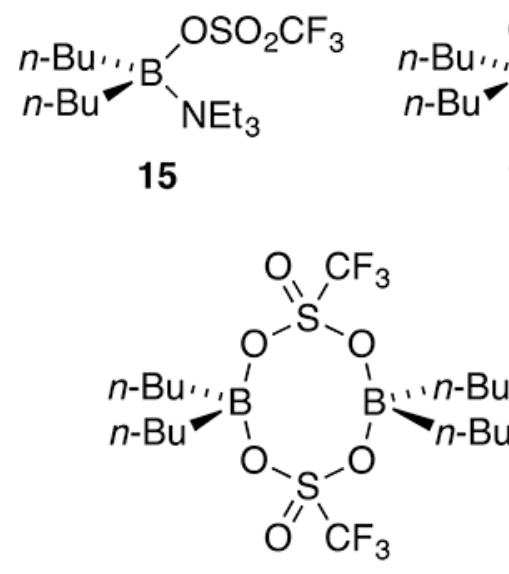

18
$\left(\mathrm{NEt}_{3}\right.$

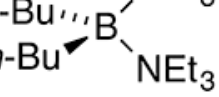

16

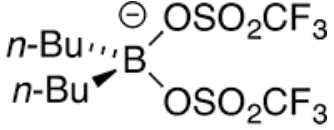

17

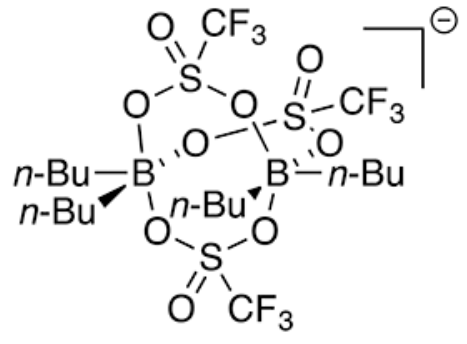

19

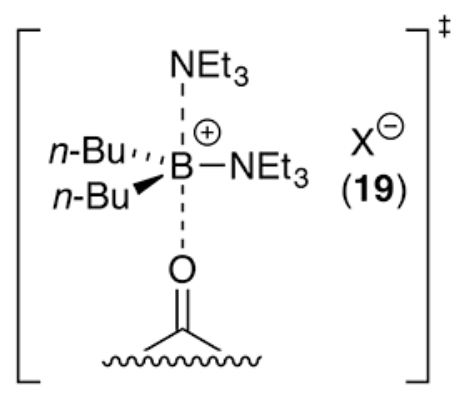

20

Chart 2.

Possible boron-containing fragments. 


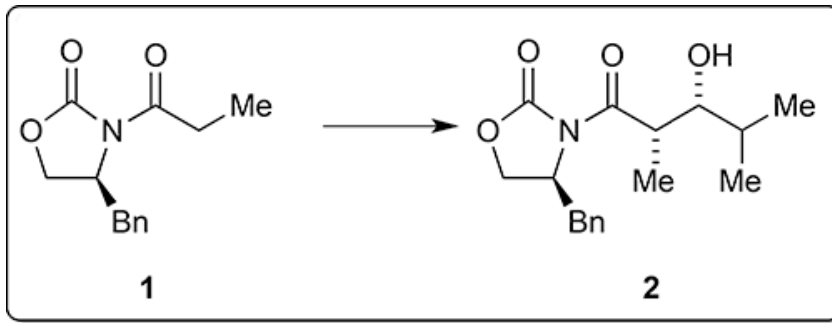<smiles>CCCCOC(C)C(C)C(=O)N1C(=O)OC[C@H]1Cc1ccccc1</smiles>

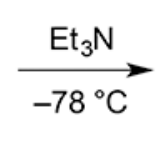

3<smiles>C/C=C(\OB(CCCC)OC(C)CC)N1C(=O)OC[C@H]1Cc1ccccc1</smiles>

$\underset{-78^{\circ} \mathrm{C}}{\stackrel{i-\mathrm{PrCHO}}{\longrightarrow}}$

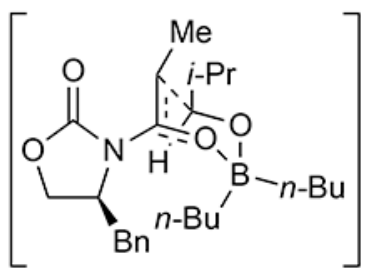

5

Scheme 1.

Mechanism of oxazolidinone-based aldol addition. 

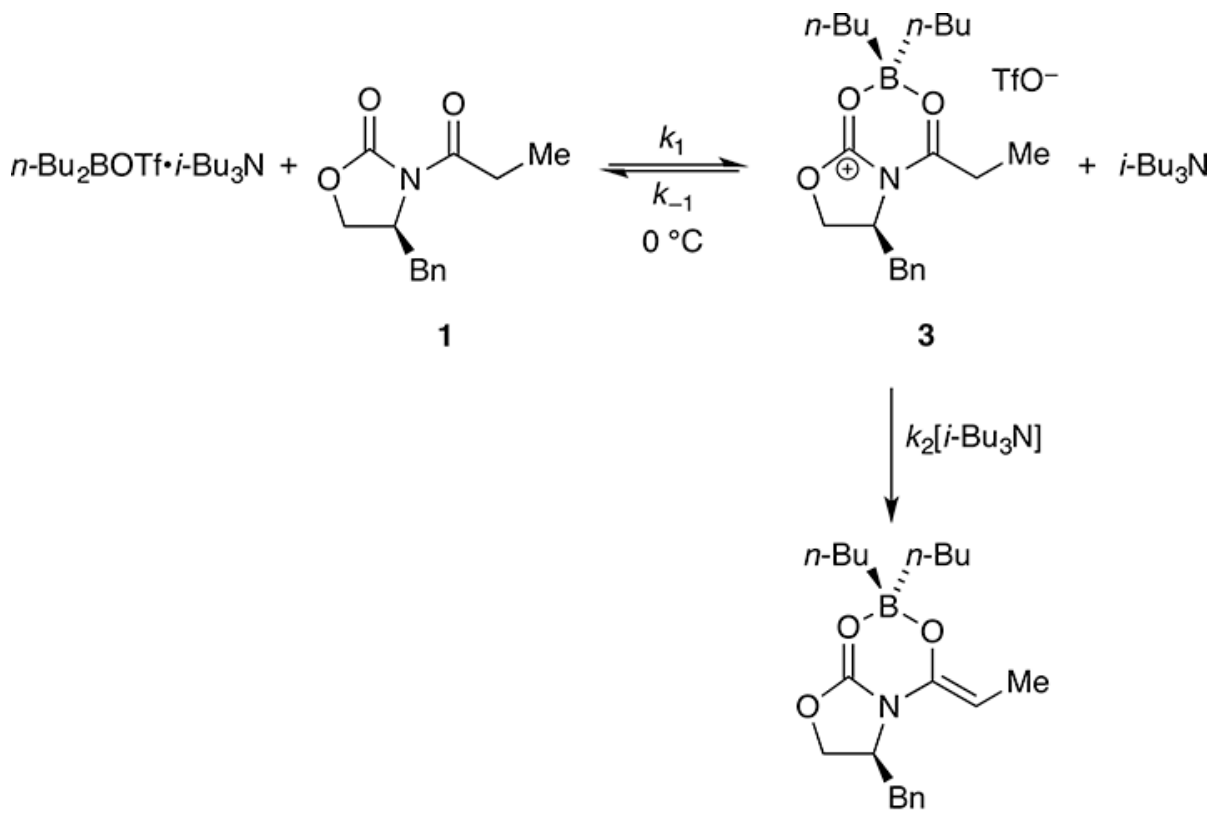

Scheme 2.

Competitive amine-mediated complexation and enolization. 
Table 1.

\begin{tabular}{|c|c|c|c|}
\hline \multirow{6}{*}{ 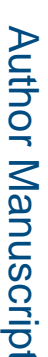 } & \multicolumn{3}{|c|}{ IR Absorbances of $\mathrm{Ke}$} \\
\hline & Compd & $\mathrm{C}=\mathrm{X}$ & $\left.\mathrm{m}^{-1}\right)$ \\
\hline & 1 & 1777 & 1704 \\
\hline & 2 & 1777 & 1704 \\
\hline & 3 & $1727^{b}$ & \\
\hline & 4 & 1706 & 1658 \\
\hline & 6 & 1777 & 1704 \\
\hline
\end{tabular}

${ }^{a} 1777$ and 1704 correspond to the oxazolidinone and propionyl group carbonyls, respectively. ${ }^{14,15}$

${ }^{b}$ Superimposed single absorbance. 